\title{
PREDIKSI BEBAN SEDIMENTASI WADUK SELOREJO MENGGUNAKAN DEBIT EKSTRAPOLASI DENGAN RANTAI MARKOV
}

\section{Prediction of Reservoir Sedimentation Selorejo Loads Using Debit Extrapolation Markov Chain}

\author{
Ernawan Setyono $^{1} \&$ Devi Ismijayanti ${ }^{2}$ \\ ${ }^{1,2}$ Jurusan Teknik Sipil - Fakultas Teknik Univ. Muhammadiyah Malang \\ Alamat Korespondensi : Jl. Raya Tlogomas 246 Malang 65144 \\ Email : ${ }^{2}$ dhevieismijayanti.1992@gmail.com
}

\begin{abstract}
Selorejo reservoirs in operation since 1970 and is expected to operate and serve the needs of water up to the year 2020. The main problem encountered in the construction and operation of reservoirs is how to keep the service life of the reservoir as planned, one of which causes the sediment that settles at the bottom of the reservoir, Based on the results of recent measurements, it is known that the dead storage capacity of 1.71 million m3. Each year has an additional volume of sediment that settles that require greater storage capacity. The results showed that in 2014 increased storage capacity for additional volume of sediment that settles at 3,223,797.64 m3 and storage capacity increased to 4,933,797.64 m3. 2015 dead storage capacity increased to 7,920,967.58 m3 and continued to increase until 2020 dead storage capacity reaches 25,585,055.30 m3. This situation shows that the volume of sediment elevation has crossed the level of low-water line $(L W L)$ and already exceeds the volume of the sediment storage capacity die before the age of reservoirs that have been planned so that it takes some effort to reduce the rate of sedimentation in the reservoir.
\end{abstract}

Keywords: reservoirs, dead storage capacity, sediment

\begin{abstract}
Abstrak
Waduk Selorejo beroperasi sejak tahun 1970 dan diharapkan dapat beroperasi dan melayani kebutuhan air hingga pada tahun 2020. Masalah utama yang dihadapi dalam pembangunan dan pengoperasian waduk adalah bagaimana menjaga agar umur layanan waduk sesuai dengan yang direncanakan, salah satunya penyebabnya adanya sedimen yang mengendap di dasar waduk. Berdasarkan hasil pengukuran terakhir, diketahui bahwa kapasitas tampungan mati 1,71 juta m3. Setiap tahun memiliki tambahan volume sedimen yang mengendap sehingga memerlukan kapasitas tampungan yang lebih besar. Hasil penelitian menunjukkan bahwa pada tahun 2014 kapasitas tampungan meningkat karena penambahan volume sedimen yang mengendap di 3,223,797.64 m3 dan kapasitas tampungan meningkat menjadi 4,933,797.64 m3. Tahun 2015 kapasitas tampungan mati meningkat menjadi $7,920,967.58 \mathrm{~m} 3$ dan terus meningkat hingga 2020 kapasitas tampungan mati mencapai 25,585,055.30 $\mathrm{m} 3$. Situasi ini menunjukkan bahwa volume elevasi sedimen telah menyeberangi tingkat garis air rendah (LWL) dan sudah melebihi volume kapasitas tampungan sedimen mati sebelum usia waduk yang telah direncanakan sehingga dibutuhkan beberapa upaya untuk mengurangi tingkat sedimentasi ke dalam reservoir.
\end{abstract}

Kata kunci: waduk, kapasitas tampungan mati, sedimen

\section{PENDAHULUAN}

Masalah utama yang dihadapi dalam pembangunan dan pengoperasian waduk adalah bagaimana menjaga agar umur layanan waduk sesuai dengan yang direncanakan disebabkan adanya sedimen yang mengendap di dasar waduk. Laju sedimentasi yang tinggi akan mengakibatkan umur layanan waduk menjadi berkurang dari yang direncanakan. Sedimentasi merupakan proses kelanjutan dari peristiwa erosi atau peristiwa terkikisnya permukaan tanah akibat air hujan. Tanah tesebut mengalir melalui cekungan-cekungan, saluran-saluran air, kemudian masuk ke sungai. Sungai selain berfungsi sebagai sarana mengalirkan 
air juga dapat berfungsi sebagai pengangkut bahanbahan material yang berupa sedimen.

Aliran air sungai yang membawa sedimen menuju ke waduk dengan kecepatan turbelensi yang besar dari aliran akan berangsur-angsur berkurang. Dibagian hulu sedimen dengan partikel ukuran yang cukup besar dan sebagian dari muatan dasar (bed load) akan mengendap membentuk delta dan partikel yang lebih kecil (suspended load) akan tetap melayang terangkut oleh aliran dan akan mengendap lebih jauh di bagian hilirnya. Partikelpartikel yang lebih kecil lagi dapat tetap melayang dan sebagian darinya mungkin akan melewati waduk bersama-sama dengan aliran yang melalui alur buangan, turbin-turbin, atau pelimpah. Sehingga terbentuklah distribusi endapan sedimen di dalam waduk.

Sedimen yang melayang (suspended load) merupakan parameter yang sangat penting dalam penentuan kualitas air sungai. Kandungan sedimen ini menunjukkan konsentrasi zat padat yang tersuspensi dalam air sungai. Salah satu kegunaan utama dengan diketahuinya kandungan sedimen ini adalah untuk mengetahui air sungai tersebut dapat dimanfaatkan untuk keperluan apa saja, juga untuk memperkirakan kecepatan proses pendangkalan waduk atau muara sungai (dapat untuk memperkirakan umur waduk). Maksud dari penelitian ini adalah untuk mengetahui hubungan debit dan kandungan sedimen yang masuk ke dalam waduk Selorejo dan mampu memprediksi volume sedimen yang mengendap di dasar waduk Selorejo hingga tahun 2020.

\section{METODE PENELITIAN}

\section{Wilayah Studi}

Waduk Selorejo merupakan salah satu bendungan di daerah Kabupaten Malang Jawa Timur yang dikelola oleh Perum Jasa tirta I. Inflow debit Waduk Selorejo berasal dari Kali Konto, Kali Kwayangan dan Kali Pinjal dengan luas daerah pengaliran 236 km2. Bagian hulu DAS Kali Konto mengalami penggundulan hutan yang menyebabkan erosi sehingga terdapat konsentrasi sedimen yang sangat tinggi pada Kali Konto.

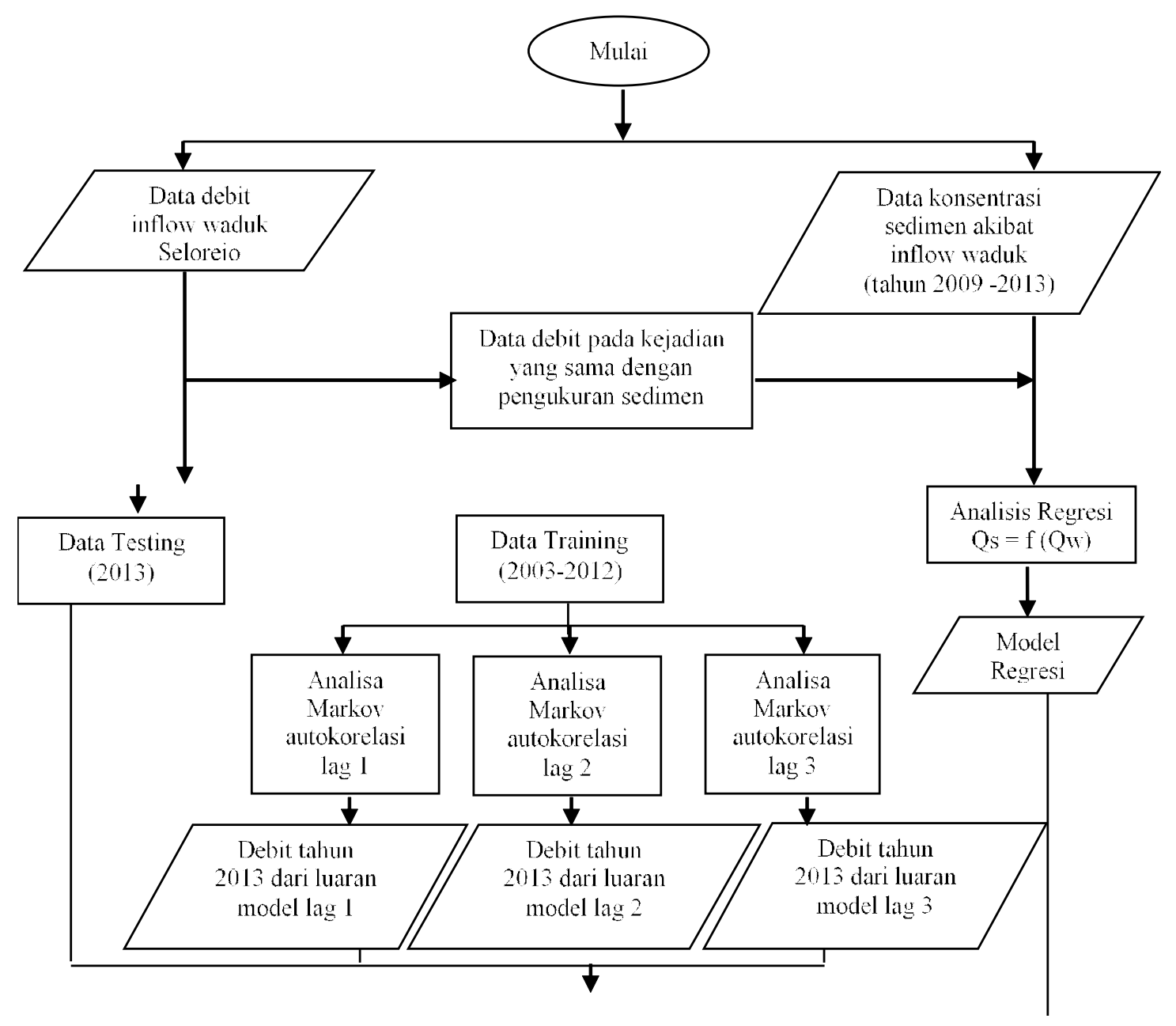



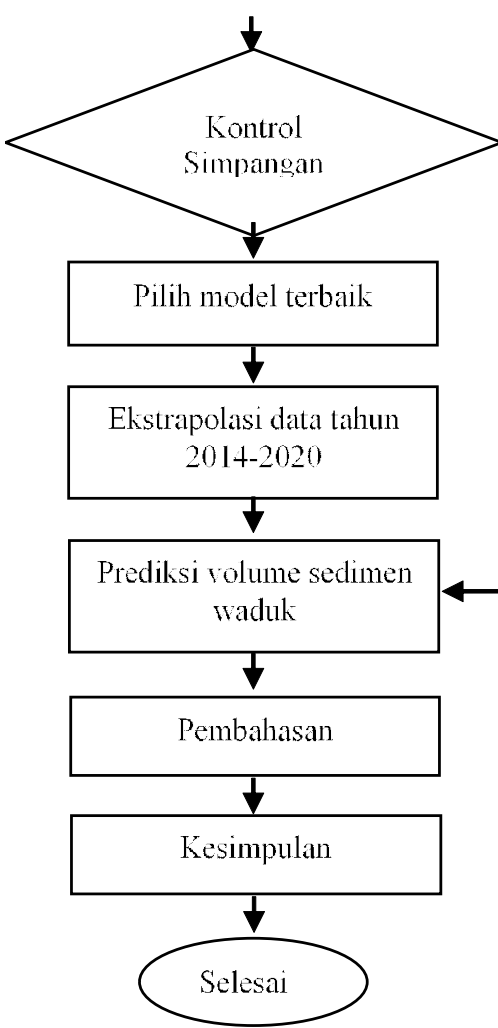

Gambar 1. Diagram Alir Proses Penelitian

\section{HASIL DAN PEMBAHASAN}

\section{Debit Inflow}

Fluktuasi aliran dari Waduk Selorejo dapat dilihat pada Gambar 1. Nilai rata-rata debit inflow minimum sebesar 2,62 $\mathrm{m}^{3} / \mathrm{dtk}$ dan nilai rata-rata debit inflow maksimum sebesar $50,43 \mathrm{~m}^{3} / \mathrm{dtk}$, sehingga rerata antara debit inflow maksimum dan debit minimum adalah sebesar $24,99 \mathrm{~m}^{3} / \mathrm{dtk}$.

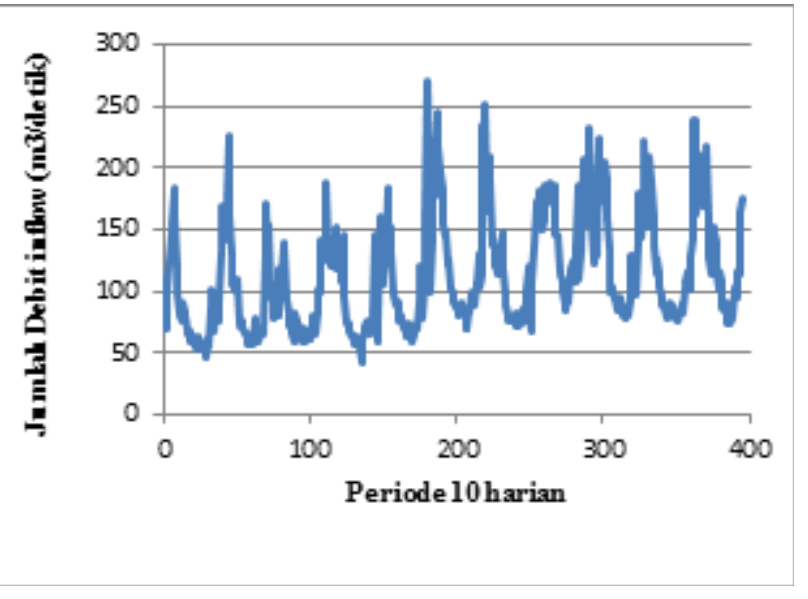

Gambar 2. Inflow Waduk 10 Harian Tahun 2003 2013

\section{Sedimen Melayang}

Debit sedimen dapat dihitung sebagai hasil perkalian antara konsentrasi sedimen dan debit air. Diasumsikan bahwa konsentrasi sedimen merata pada seluruh bagian penampang melintang sungai dan debit aliran diukur bersamaan dengan pengukuran sedimen dengan menggunakan persamaan (2.1) yang disajikan pada tabel 1 .

\section{Kurva Debit Inflow $\left(Q_{w}\right)$ dan Debit Sedimen Melayang $\left(\mathbf{Q}_{\mathrm{s}}\right)$}

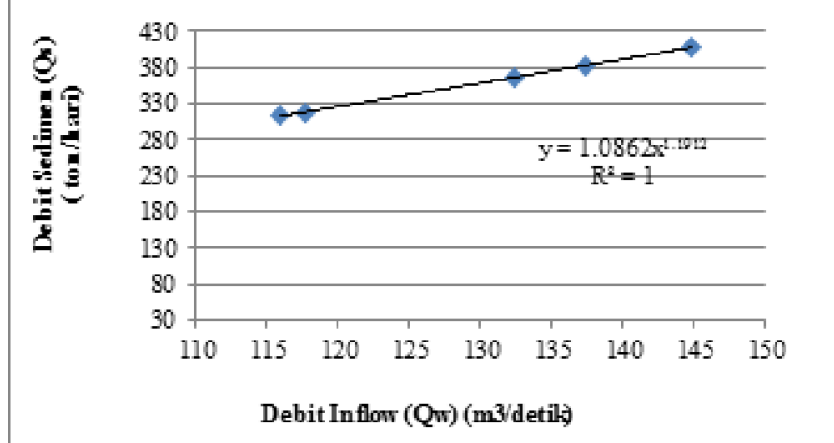

Gambar 3. Grafik hubungan antara debit inflow (Qw) dan debit sedimen (Qs) 
Dengan mengetahui debit sedimen dan debit aliran yang masuk ke dalam waduk, dibuat hubungan antara dua variabel yang digambarkan dalam bentuk kurva $\mathrm{Q}_{\mathrm{w}}$ dan $\mathrm{Q}_{\mathrm{s}}$ atau dapat juga disebut lengkung laju debit-sedimen (sediment-discharge rating curve). debit aliran yang masuk ke dalam waduk dan debit sedimen memiliki hubungan yang kuat dikarenakan nilai korelasinya yang mencapai 1 . Dari hubungan dua variabel didapatkan persamaan $\mathrm{Q}_{\mathrm{s}}=$ $1,0862 \mathrm{Q}_{\mathrm{w}}^{1,119151}$

\section{Sedimen Melayang}

Debit sedimen dapat dihitung sebagai hasil perkalian antara konsentrasi sedimen dan debit air. Diasumsikan bahwa konsentrasi sedimen merata pada seluruh bagian penampang melintang sungai dan debit aliran diukur bersamaan dengan pengukuran sedimen dengan menggunakan persamaan (2.1) yang disajikan pada tabel 1.

Tabel 1. Debit Sedimen Melayang pada tahun 2009-2013

\begin{tabular}{cccc}
\hline Tahun & $\begin{array}{c}\text { Qw } \\
\mathrm{m}^{3} / \mathrm{dtk}\end{array}$ & $\begin{array}{c}\mathrm{C} \\
\mathrm{mg} / \mathrm{l}\end{array}$ & $\begin{array}{c}\mathrm{Qs} \\
\text { ton/hari }\end{array}$ \\
\hline 2009 & 115,81 & 33,51 & 335,30 \\
2010 & 144,72 & 32,22 & 402,84 \\
2011 & 132,42 & 49,21 & 563,01 \\
2012 & 117,61 & 26,05 & 264,70 \\
2013 & 137,30 & 23,65 & 280,56 \\
\hline
\end{tabular}

Sumber :Hasil Perhitungan

\section{Perpanjangan Data Debit}

Untuk meramalkan atau memprediksi debit sedimen yang masuk kedalam waduk dari tahun 2014 sampai dengan tahun 2020 dilakukan perpanjangan data debit dengan menggunakan model markov lag 1, lag 2, dan lag 3 .

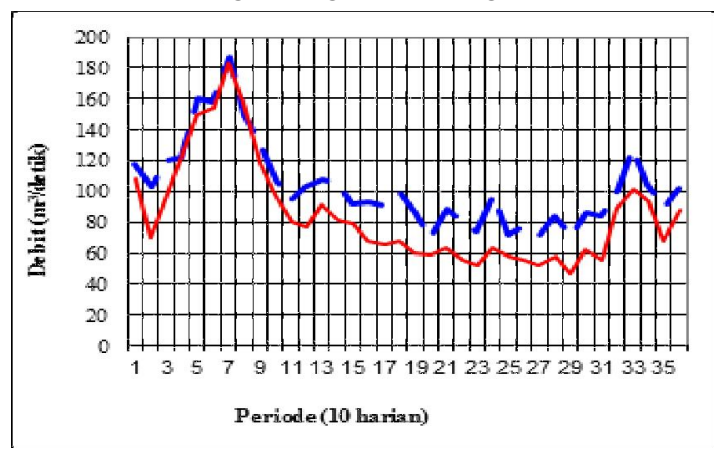

Gambar 4. Grafik Perbandingan Debit Amatan dan Debit model Markov autokorelasi lag satu

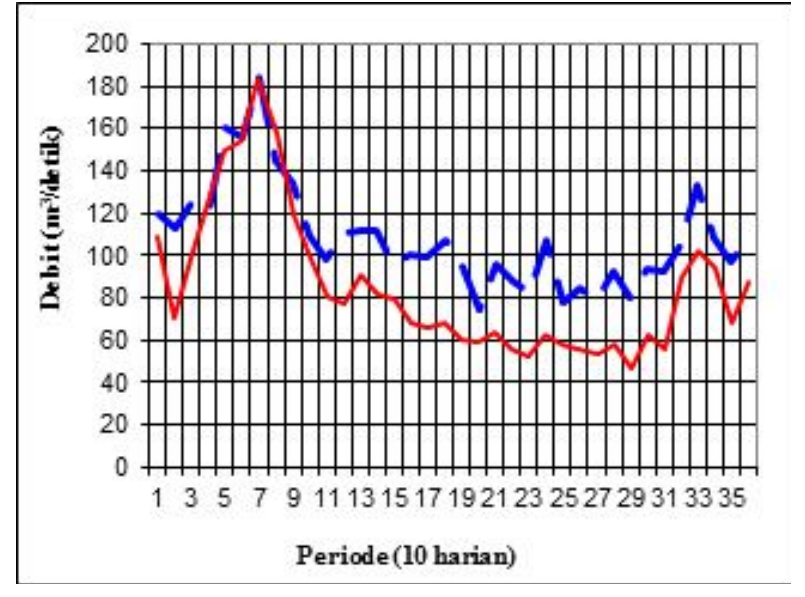

Gambar 5. Grafik Perbandingan Debit Amatan dan Debit model Markov autokorelasi lag dua

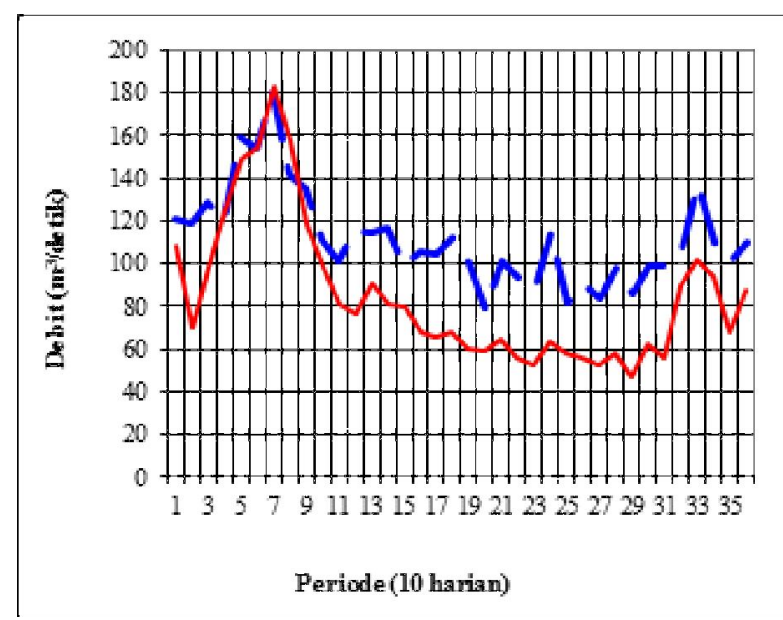

Gambar 6. Grafik Perbandingan Debit Amatan dan Debit model Markov autokorelasi lag tiga

\section{Pengujian Model}

Hasil perbandingan data debit tahun 2013 (data testing) dan data hasil model disajikan pada gambar 6,7, dan 8 .

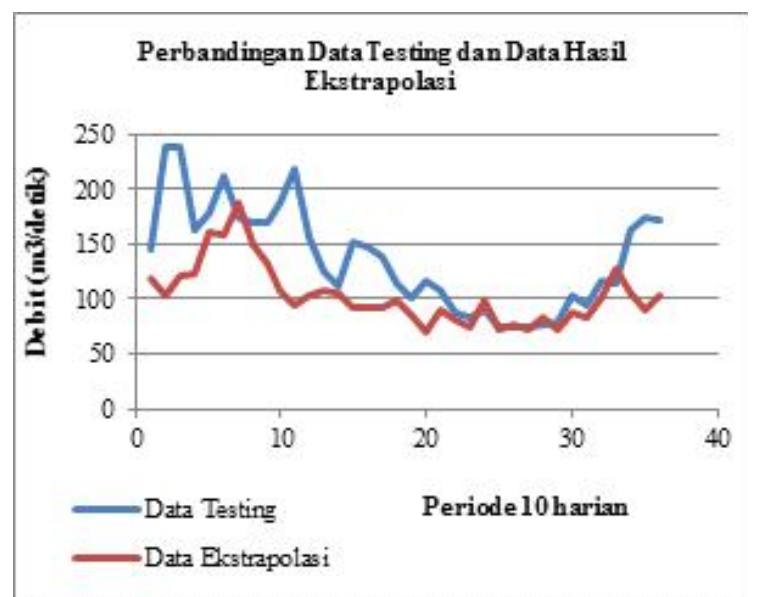

Gambar 7. Grafik Perbandingan Debit Testing dan Debit model Markov autokorelasi lag satu 


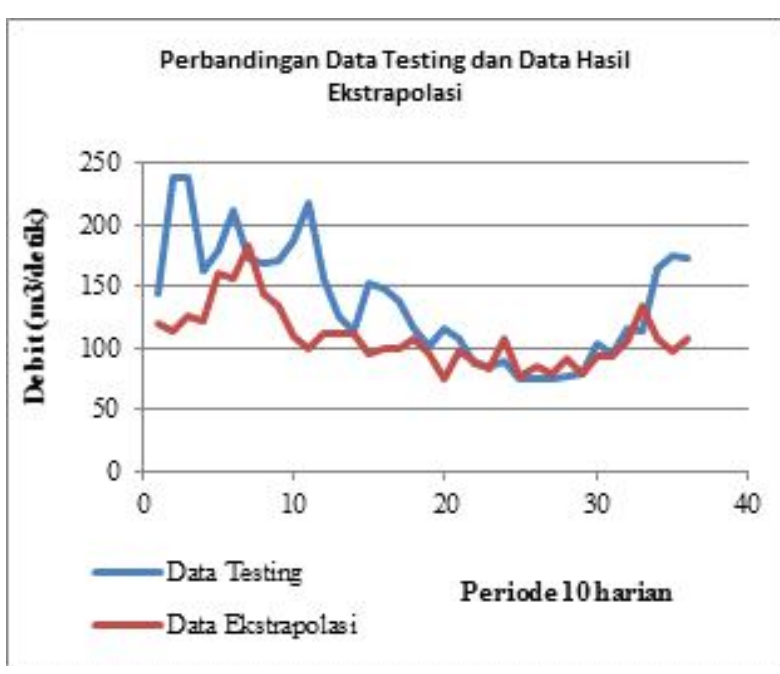

Gambar 8 . Grafik Perbandingan Debit Testing dan Debit model Markov autokorelasi lag dua

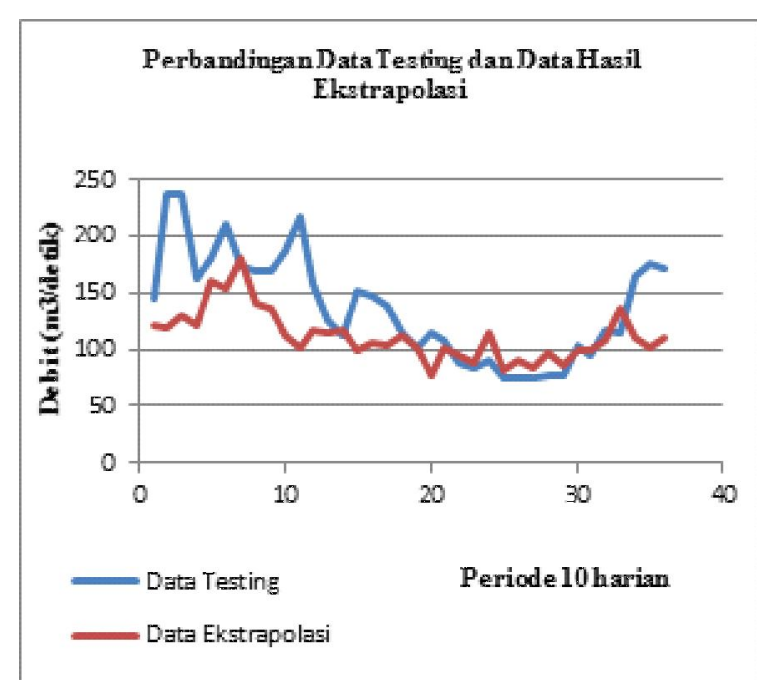

Gambar 9. Grafik Perbandingan Debit Testing dan Debit model Markov autokorelasi lag tiga

\section{Debit Inflow Hasil Ekstrapolasi}

Tabel 2. Debit Inflow Hasil Ekstrapolasi Tahun 2013-2020

\begin{tabular}{|c|c|c|c|c|c|c|c|c|c|}
\hline \multicolumn{2}{|c|}{ Periode } & 2013 & 2014 & 2015 & 2016 & 2017 & 2018 & 2019 & 2020 \\
\hline \multirow{5}{*}{ Jan } & 1 & 120,78 & 102,56 & 105,15 & 136,95 & 98,63 & 169,40 & 140,39 & 158,20 \\
\hline & 2 & 118,45 & 125,24 & 107,71 & 149,24 & 85,31 & 136,73 & 217,57 & 161,85 \\
\hline & 3 & 128,61 & 155,06 & 117,78 & 168,26 & 90,69 & 134,06 & 187,34 & 158,65 \\
\hline & 1 & 119,89 & 179,41 & 120,01 & 126,05 & 149,29 & 167,24 & 201,54 & 159,38 \\
\hline & 2 & 159,51 & 142,16 & 125,27 & 143,61 & 130,93 & 172,53 & 173,31 & 164,75 \\
\hline \multirow[t]{3}{*}{ Feb } & 3 & 154,14 & 148,12 & 98,03 & 129,55 & 135,53 & 189,43 & 196,95 & 140,09 \\
\hline & 1 & 180,33 & 180,40 & 118,47 & 123,47 & 132,52 & 205,14 & 175,28 & 152,72 \\
\hline & 2 & 141,26 & 200,47 & 131,10 & 143,32 & 130,93 & 210,12 & 130,46 & 152,62 \\
\hline \multirow[t]{3}{*}{ Mar } & 3 & 135,24 & 151,93 & 139,35 & 140,51 & 170,28 & 178,73 & 133,45 & 167,37 \\
\hline & 1 & 111,26 & 144,85 & 157,31 & 128,35 & 127,52 & 166,04 & 155,97 & 173,56 \\
\hline & 2 & 101,43 & 108,26 & 143,66 & 140,55 & 146,93 & 140,43 & 124,58 & 182,66 \\
\hline \multirow[t]{3}{*}{ Apr } & 3 & 115,76 & 111,55 & 102,10 & 140,15 & 139,44 & 148,59 & 139,46 & 181,46 \\
\hline & 1 & 114,56 & 131,10 & 98,81 & 125,43 & 121,94 & 136,53 & 113,78 & 174,67 \\
\hline & 2 & 116,02 & 122,48 & 90,42 & 113,31 & 123,58 & 143,98 & 141,12 & 174,63 \\
\hline \multirow[t]{3}{*}{ Mei } & 3 & 98,94 & 136,24 & 111,16 & 147,58 & 102,27 & 143,07 & 164,93 & 184,74 \\
\hline & 1 & 105,17 & 92,33 & 93,15 & 105,22 & 127,67 & 120,79 & 126,60 & 157,84 \\
\hline & 2 & 104,22 & 98,79 & 96,33 & 111,03 & 111,05 & 116,23 & 119,08 & 149,54 \\
\hline \multirow[t]{3}{*}{ Jun } & 3 & 112,44 & 105,20 & 92,80 & 90,61 & 105,88 & 108,31 & 125,97 & 129,16 \\
\hline & 1 & 100,05 & 106,55 & 119,95 & 106,94 & 115,06 & 119,31 & 101,22 & 143,88 \\
\hline & 2 & 78,05 & 112,71 & 105,43 & 83,75 & 101,82 & 117,06 & 100,31 & 129,87 \\
\hline \multirow[t]{3}{*}{ Jul } & 3 & 101,46 & 99,51 & 117,96 & 85,49 & 112,24 & 124,15 & 113,20 & 119,43 \\
\hline & 1 & 93,92 & 89,43 & 105,65 & 103,70 & 90,08 & 111,59 & 109,74 & 111,25 \\
\hline & 2 & 87,84 & 99,91 & 90,27 & 96,72 & 87,86 & 113,27 & 109,93 & 122,96 \\
\hline \multirow[t]{3}{*}{ Agt } & 3 & 114,01 & 78,06 & 94,28 & 84,89 & 101,85 & 109,90 & 107,56 & 121,38 \\
\hline & 1 & 81,49 & 91,94 & 103,48 & 77,02 & 84,42 & 106,81 & 103,97 & 108,34 \\
\hline & 2 & 90,15 & 122,45 & 94,67 & 79,84 & 93,18 & 101,39 & 103,17 & 143,79 \\
\hline \multirow[t]{3}{*}{ Sep } & 3 & 83,60 & 99,81 & 111,86 & 86,78 & 89,70 & 111,93 & 113,18 & 135,05 \\
\hline & 1 & 97,63 & 88,18 & 81,63 & 88,89 & 94,69 & 118,85 & 93,24 & 142,66 \\
\hline & 2 & 85,56 & 81,41 & 94,09 & 95,60 & 91,99 & 119,56 & 106,24 & 130,17 \\
\hline \multirow[t]{3}{*}{ Okt } & 3 & 99,06 & 89,86 & 103,25 & 118,17 & 102,71 & 136,62 & 128,06 & 141,35 \\
\hline & 1 & 98,98 & 111,45 & 107,08 & 97,02 & 142,57 & 103,53 & 108,59 & 190,81 \\
\hline & 2 & 106,92 & 93,18 & 101,61 & 87,96 & 101,56 & 107,84 & 127,20 & 124,43 \\
\hline \multirow[t]{3}{*}{ Nov } & 3 & 136,96 & 136,08 & 102,81 & 109,84 & 96,23 & 117,09 & 141,15 & 153,12 \\
\hline & 1 & 109,96 & 168,23 & 118,22 & 117,46 & 120,77 & 108,28 & 109,66 & 195,40 \\
\hline & 2 & 101,08 & 118,79 & 113,35 & 99,77 & 160,69 & 146,25 & 114,23 & 160,73 \\
\hline Des & 3 & 109,73 & 142,85 & 158,04 & 141,04 & 226,61 & 137,36 & 126,56 & 151,55 \\
\hline
\end{tabular}


Berdasarkan nilai RMSE dan MAE, digunakan model Markov lag-3 untuk memperpanjang data debit tahun 2014-2020. Debit hasil ektstrapolasi tahun 2014-2020 disajikan pada tabel 2 di atas.

\section{Volume Sedimen Melayang}

Debit sedimen melayang untuk tahun 2014 sampai dengan 2020 dapat diprediksikan dengan menggunakan persamaan regresi hasil dari hubungan antara $Q_{w}$ dan $Q_{s}$ dan data debit hasil ekstrapolasi 2014 sampai dengan 2020. Debit sedimen dapat dihitung yang disajikan pada pada tabel sebagai berikut.
Tabel 3. Rekapitulasi volume sedimen pertahun

\begin{tabular}{cccc}
\hline Tahun & $\mathrm{t}$ & $\begin{array}{c}\text { Q-sedimen } \\
\mathrm{m}^{3} / \text { tahun }\end{array}$ & $\begin{array}{c}\text { Q-sedimen } \\
\mathrm{m}^{3}\end{array}$ \\
\hline 2014 & 44 & $140.900,25$ & $6.199 .610,85$ \\
2015 & 45 & $125.248,22$ & $5.636 .169,70$ \\
2016 & 46 & $131.302,47$ & $6.039 .913,80$ \\
2017 & 47 & $136.125,08$ & $6.397 .878,83$ \\
2018 & 48 & $161.430,98$ & $7.748 .687,12$ \\
2019 & 49 & $157.138,27$ & $7.699 .775,22$ \\
2020 & 50 & $183.053,87$ & $9.152 .693,62$ \\
\hline
\end{tabular}

Sumber : Hasil Perhitungan

\section{Efisiensi Tangkapan Waduk (Trap Efficiency)}

Untuk mengetahui seberapa besar sedimen melayang yang mengendap di waduk harus dicari nilai trap efficiency-nya yang dihitung menggunakan metode Brune. Metode Brune menggunakan data masukan berupa perbandingan perbandingan antara kapasitas waduk (C) dengan aliran air rata-rata yang masuk ke dalam waduk pada periode yang ditinjau (I).

Tabel 4. Perhitungan Trap Efficiency Tahun 2014-2017

\begin{tabular}{ccccc}
\hline Uraian & 2014 & 2015 & 2016 & 2017 \\
\hline $\begin{array}{c}\text { Kapasitas } \\
\text { Tampungan } \\
\left(\mathrm{m}^{3}\right)\end{array}$ & $62,30 \times 10^{6}$ & $62,30 \times 10^{6}$ & $62,30 \times 10^{6}$ & $62,30 \times 10^{6}$ \\
Inflow $\left(\mathrm{m}^{3}\right)$ & $3.772 .697 .669,5$ & $3.431 .993 .029,1$ & $3.563 .198 .261,2$ & $3.667 .172 .453,2$ \\
C/I & 0,017 & 0,018 & 0,017 & 0,017 \\
Trap & $52 \%$ & $53 \%$ & $52 \%$ & $52 \%$ \\
Efficiency & & &
\end{tabular}

Tabel 5. Perhitungan Trap Efficiency Tahun 2018-2020

\begin{tabular}{cccc}
\hline Uraian & 2018 & 2019 & 2020 \\
\hline Kapasitas & & & \\
Tampungan & $62,30 \times 10^{6}$ & $62,30 \times 10^{6}$ & $62,30 \times 10^{6}$ \\
$\left(\mathrm{~m}^{3}\right)$ & & & \\
Inflow $\left(\mathrm{m}^{3}\right)$ & $4.231 .992 .808,2$ & $4.134 .248 .551,5$ & $4.708 .856 .829,9$ \\
C/I & 0,015 & 0,015 & 0,013 \\
Trap & $47 \%$ & $47 \%$ & $43 \%$ \\
Efficiency & & & \\
\hline
\end{tabular}

Tabel 6. Volume Sedimen Melayang yang Mengendap di Waduk

\begin{tabular}{|c|c|c|c|c|c|c|c|}
\hline Uraian & 2014 & 2015 & 2016 & 2017 & 2018 & 2019 & 2020 \\
\hline Debit Sedimen & $\begin{array}{l}6.199 .6 \\
10,85\end{array}$ & $\begin{array}{l}5.636 .169, \\
70\end{array}$ & $\begin{array}{l}6.039 .913, \\
80\end{array}$ & $\begin{array}{l}6.397 .87 \\
8,83\end{array}$ & $\begin{array}{l}7.748 .68 \\
7,12\end{array}$ & 7.699.775,22 & $8.705 .976,21$ \\
\hline $\begin{array}{l}\text { Trap Efficiency } \\
\text { Volume }\end{array}$ & $52 \%$ & $53 \%$ & $52 \%$ & $52 \%$ & $47 \%$ & $47 \%$ & $43 \%$ \\
\hline $\begin{array}{l}\text { Sedimen yang } \\
\text { mengendap di } \\
\text { waduk }\end{array}$ & $\begin{array}{l}3.223 .7 \\
97,64\end{array}$ & $\begin{array}{l}2.987 .169, \\
94\end{array}$ & $\begin{array}{l}3.140 .755, \\
18\end{array}$ & $\begin{array}{l}3.326 .89 \\
6,99\end{array}$ & $\begin{array}{l}3.641 .88 \\
2,94\end{array}$ & $3.618 .894,35$ & $3.935 .658,26$ \\
\hline
\end{tabular}


Tabel 7. Rekapitulasi Kapasitas Tampungan Mati

\begin{tabular}{cccc}
\hline Tahun & $\begin{array}{c}\text { Volume Kapasitas Waduk } \\
\mathrm{m}^{3}\end{array}$ & $\begin{array}{c}\text { Volume Sedimen } \\
\mathrm{m}^{3}\end{array}$ & $\begin{array}{c}\text { Elevasi } \\
\mathrm{m}\end{array}$ \\
\hline 2013 & $1.710 .000,00$ & 0 & +594 \\
2014 & $4.933 .797,64$ & $3.223 .797,64$ & $+603,8$ \\
2015 & $7.920 .967,58$ & $2.987 .169,94$ & +607 \\
2016 & $11.061 .722,76$ & $3.140 .755,18$ & $+610,2$ \\
2017 & $14.388 .619,75$ & $3.326 .896,99$ & $+612,4$ \\
2018 & $18.030 .502,69$ & $3.641 .882,94$ & +615 \\
2019 & $21.649 .397,05$ & $3.618 .894,35$ & $+616,5$ \\
2020 & $25.585 .055,30$ & $3.935 .658,26$ & $+618,1$ \\
\hline
\end{tabular}

Sumber : Hasil Perhitungan

Dengan mengetahui volume kapasitas waduk hingga tahun 2014 sampai dengan tahun 2020, dapat diketahui ketinggian (elevasi) sedimen yang mengendap di kapasitas tampungan mati berdasarkan grafik lengkung kapasitas waduk Selorejo seperti gambar dibawah ini.

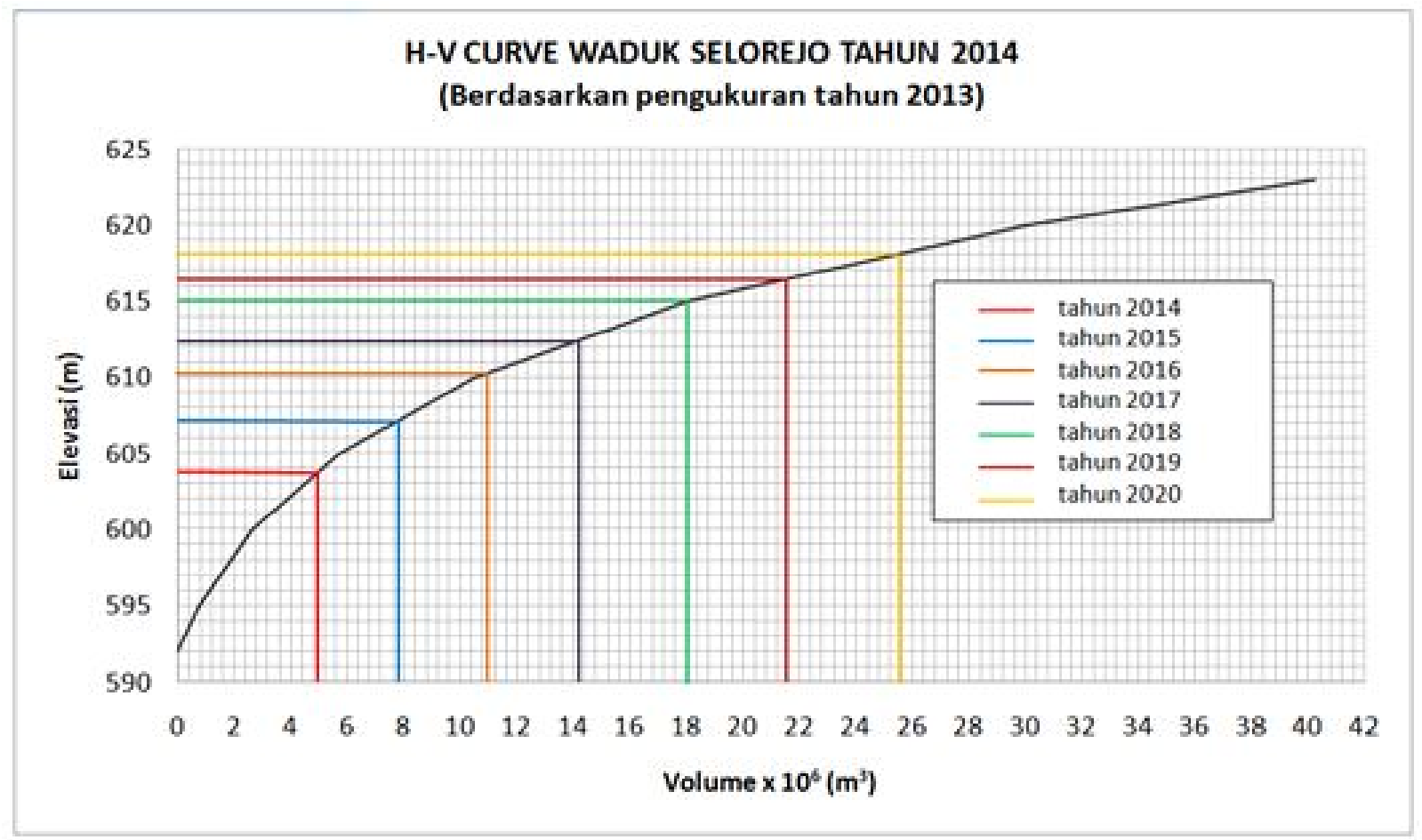

Gambar 10. Grafik Lengkung Kapasitas Waduk Selorejo

\section{KESIMPULANDANSARAN}

Kesimpulan

Dengan analisa dan perhitungan yang telah dilakukan dapat disimpulkan bahwa :

- Debit aliran yang masuk kedalam waduk Selorejo memiliki hubungan erat dengan debit sedimen dengan nilai koefisien determinasi $\left(\mathrm{R}^{2}\right)=1$ dan nilai korelasi $=1$. Dari hubungan dua variabel didapatkan persamaan $Q_{s}=1,0862$ $\mathrm{Q}_{\mathrm{w}}{ }^{1,119151}$.

- $\quad$ Debit sedimen yang masuk pada tahun 2014 sebesar 6.199.610,85 m³ tahun 2015 sebesar
$5.636 .169,70 \mathrm{~m}^{3}$, tahun 2016 sebesar $6.039 .913,80 \mathrm{~m}^{3}$, tahun $20176.397 .878,83 \mathrm{~m}^{3}$, tahun 2018 sebesar $7.748 .687,12 \mathrm{~m}^{3}$. tahun 2019 sebesar 7.699.775,22 $\mathrm{m}^{3}$, dan tahun 2020 sebesar 9.152.693,62 $\mathrm{m}^{3}$.

- Volume sedimen yang mengendap tahun 2014 sebesar 3.223.797,64 $\mathrm{m}^{3}$ dengan trap efficiency sebesar 52\%, tahun 2015 sebesar $2.987 .169,94 \mathrm{~m}^{3}$ dengan trap efficiency sebesar 53\%, tahun 2016 sebesar $3.140 .755,18 \mathrm{~m}^{3}$ dengan trap efficiency sebesar 52\%, tahun 2017 sebesar $3.326 .896,99 \mathrm{~m}^{3}$ dengan trap efficiency sebesar 52\%, tahun 2018 sebesar 
$3.641 .882,94 \mathrm{~m}^{3}$ dengan trap efficiency sebesar 47\%, tahun 2019 sebesar $3.618 .894,35 \mathrm{~m}^{3}$ dengan trap efficiency sebesar 47\%, dan tahun 2020 sebesar $3.935 .658,26 \mathrm{~m}^{3}$ dengan trap efficiency sebesar $43 \%$,

- Kapasitas tampungan mati menjadi semakin besar akibat penambahan volume sedimen yang mengendap. Kapasitas tampungan mati pada tahun 2014 mencapai 4.933.797,64 $\mathrm{m}^{3}$, tahun 2015 mencapai 7.920.967,58 $\mathrm{m}^{3}$, tahun 2016 mencapai $11.061 .722,76 \mathrm{~m}^{3}$, tahun 2017 mencapai $14.388 .619,75 \mathrm{~m}^{3}$. tahun 2018 mencapai 18.030.502,69 $\mathrm{m}^{3}$, tahun 2019 mencapai $21.649 .397,05 \mathrm{~m}^{3}$, dan tahun 2020 mencapai 25.585.055,30 $\mathrm{m}^{3}$.

- Besarnya sedimen yang mengendap di dalam waduk hingga tahun 2020 sudah melebihi kapasitas tampungan mati sebelum umur rencana waduk yang sudah direncanakan sehingga diperlukan beberapa usaha untuk menekan laju sedimentasi yang masuk ke dalam waduk.

\section{Saran}

Mengingat relatif besarnya volume sedimen yang mengendap didasar waduk Selorejo sampai dengan tahun 2020 dimana sudah melebihi kapasitas tampungan mati, maka perlu dilakukan pengerukan agar waduk tetap dapat beroperasi dan juga perlunya dilakukan usaha-usaha untuk menekan laju sedimentasi yang masuk ke dalam waduk, salah satunya dengan konservasi lahan.

\section{DAFTAR PUSTAKA}

Asdak, Chay. 2002. Hidrologi dan Pengelolaan Daerah Aliran Sungai. Gadjah Mada University Press:Yogyakarta

Dyah Ari W. 2004. Tesis:Evaluasi Penggunaan Lengkung Laju Debit Sedimen (SedimentDischarge Rating Curve) untuk Memprediksi Sedimen Melayang. Skripsi. Universitas Diponegoro:Semarang

Malik, Rachmad Sangaji. Kajian Distribusi Sedimentasi Waduk Wonorejo, Tulungagung-Jawa Timur (Tahun 20082011). Skripsi. Universitas Muhammadiyah Malang
Soemarto. 1987. Hidrologi Teknik. Usaha Nasional:Surabaya

Soewarno. 1991. Hidrologi Pengukuran dan Pengolahan Data Aliran Sungai (Hidrometer).Nova: Bandung

Walpole, Ronald E dan Myers, Raymond H. 1995. Ilmu Peluang dan Statistika untuk Insinyur dan Ilmuwan. ITB:Bandung. 